\title{
Fungi Isolated from Traditional and Exotic Apple Varieties from Portugal and Patulin Production
}

\author{
C.M.M. Almeida ${ }^{\mathrm{a},{ }^{*}}$ and M.M. Lopes ${ }^{\mathrm{b}}$ \\ aUniversidade de Lisboa, Faculdade de Farmácia, Departamento de Ciências Toxicológicas e \\ Bromatológicas, Av. Prof. Gama Pinto, 1649-003- Lisboa, Portugal \\ ${ }^{b}$ Universidade de Lisboa, Faculdade de Farmácia, Departamento de Microbiologia e Imunologia, Av. Prof. \\ Gama Pinto, 1649-003- Lisboa, Portugal
}

\begin{abstract}
The objective of our study was to examine the effects of cultivar type on developed fungi species and evaluate the potential for patulin production by fungi. In addition, patulin diffusion was also investigated. The experiments were carried out in traditional (Bravo de Esmolfe) and exotic apples (Golden, Starking, Fuji, Reineta Parda and Gala Galaxy) varieties from Portugal. High-performance liquid chromatography with solid phase extraction and UV detection (SPEHPLC-UV) was validated and used to analyze patulin in the apple. The most prevalent fungal population was Penicillium spp and $27 \%$ of rotten fruits had patulin. Fungi of the genera Cladosporium spp., Alternaria spp., Fusarium spp. and Aspergillus spp. were also found even in apples without patulin production. The variety with the highest production of patulin was Bravo Esmolfe, however this variety showed the lowest prevalence of Penicillium spp. compared to other varieties of apples where was detected patulin.

Patulin was not detected in any apples of Fuji and Gala varieties, despite having been identified fungi usually associated with the production of patulin. Thus, these two varieties are presented as the most suitable for the production of the apple based-foods.
\end{abstract}

Keywords: Patulin, Mycotoxins, Apples, Toxigenic fungi, HPLC, SPE.

\section{INTRODUCTION}

In the last two decades, there has been increasing concern in the scientific community about the occurrence of mycotoxins in commodities and their impact on human health.

Mycotoxins are a class of highly toxic compounds, secondary metabolites, produced under particular environmental conditions, such us temperature and moisture by certain fungi or moulds, belonging mainly to the Aspergillus, Penicillium and Fusarium genera. The presence of mycotoxins in food and feed may affect human and animal health as they may cause many different adverse health effects such as induction of cancer and mutagenicity, as well as estrogenic, gastrointestinal and kidney disorders. Some mycotoxins are also immunosuppressive reducing resistance to infectious disease [1].

Patulin (PAT) is a mycotoxin produced by certain species of fungi, often present in apples and apple derivatives like juice and puree. Acute symptoms of PAT consumption can include agitation, convulsions, edema, ulceration, intestinal inflammation and vomiting [2]. Chronic health effects of PAT include genotoxicity,

\footnotetext{
*Address correspondence to this author at the Universidade de Lisboa, Faculdade de Farmácia, Departamento de Ciências Toxicológicas e Bromatológicas, Av. Prof. Gama Pinto, 1649-003- Lisboa, Portugal;

Tel: +351217946400; Fax: +351 217946470; E-mail: calmeida@ff.ulisboa.pt
}

immunotoxicity, and neurotoxicity in rodents, while its effects on humans are not clear yet [3].

Patulin is genotoxic but no adequate evidence exists for carcinogenicity in experimental animals and humans. It is not classifiable as to its carcinogenicity to humans and it is included in Group 3 of the International Agency for Research on Cancer [4].

Patulin, a polyketide lactone (4-hydroxy-4H-furo[3,2c]pyran-2(6H)-one) is a toxic secondary metabolite of a number of fungal species belonging to the genera Penicillum, Aspergillus and Byssochlamys, which can infect many types of foods, like fruits [5].

Several Penicillium species were identified as producing PAT but Penicillium expansum is the specie most often found in contaminated food and it was been referred as the main producer of PAT. This fungus causes rotting of fruit, with formation of blue mold $[6,7$, 8].

The occurrence of PAT in different food commodities has been the subject of many research investigations in Europe: Portugal [9], Spain [10,11] Belgium [5]; Italy [12]; Greece [13] and Holland [14]. However, studies should not be limited to occurrence studies, but should include studies relating to the fungi development on all apples varieties and its relationship with the production of PAT. These results can be managed through the selection of apples varieties with 
lower production of PAT and can contribute to a lower health risk associate to consumption of apple basedfoods.

Apple juices are the most important source of PAT in human diet [15]. A maximum of $50 \mathrm{mg} / \mathrm{L}$ for PAT in apple juice was considered acceptable by the Codex Alimentarius Commission. The European Union adopted the same maximum level of $50 \mathrm{mg} / \mathrm{L}$ for apple juice but the maximum level allowed for apple products intended for infants and young children is $10 \mathrm{mg} / \mathrm{kg}$ [16].

The principal risk arises when unfit fruit is used for the production of juices and other processed products. Apples and apple products are excellent substrates for Penicillium expansum, the causal agent of "blue mould rot", to produce the PAT. Bruises, skin breaks and other physical damage within these apples provide a perfect entry for $P$. expansum and other patulinproducing species into the fruit [17] but PAT can be found in healthy tissues [18].

The apples for juice production are generally of poor quality because part of apples harvested is not suitable for fresh market and they are generally used to production of juice. Usually, these apples and those ones from storage rooms (lower quality as result of longer time in cold storage) are used for apple juice production; as a result, the use of low quality raw material leads to highly patulin-contaminated juice. For this reason, PAT contamination in apples is a cause of concern in food industry, in both fruit and juice industry.

From a human health and food safety perspective, it is important to gain a good understanding of levels of PAT in individual commodities to assess exposure. However, only through understanding which fungi are responsible for toxin production can preventative strategies be developed [19].

There are several studies relating PAT accumulation in apples during storage, the factors that influencing PAT production and the role of processing on PAT levels in juices [11-22]. However, the studies relating to apples varieties in fungi development are scarce $[23,24]$, especially in apples varieties produced in Portugal.

Martins and collaborators [23] reported the occurrence of PAT in 351 Portuguese apples with small rotten spots. In some of these samples the level of PAT was higher than $80 \mathrm{mg} / \mathrm{kg}$. These findings indicate that there may be a risk of human exposure to PAT through the consumption of juices and jams manufactured with apples with small rotten areas.

Apples are one of the most consumed fruits worldwide and, there are various types of apples, which grow in different parts of the world. In Portugal, apples are cultivated in several regions located mainly at the north region and they are destined to consumption as fruit, juice or jam. The apples production in Portugal was 247229 tonnes in 2011 [25].

According to FAOSTAT, in 2009 an average of $28.10 \mathrm{~kg}$ of apples per capita per year were consumed in Portugal, this consumption was equal to oranges and mandarins $(28.00 \mathrm{~kg} / \mathrm{capita} / \mathrm{year})$ and it represents more than $50 \%$ of the consumption of the other fruits, which accounted for $41.90 \mathrm{~kg}$ per capita 2011 [25]. These values showing its importance in the Portuguese diet. The remaining apple production is used in the production of juices and jams. The variety of apples used in juices and jams industry depends on the individual production of each variety, which vary each year.

Thus, it is important to evaluate the occurrence of fungi genera in apples varieties and PAT accumulation in apples during storage in these varieties. Therefore, the aim of the present study was: (1) to determine the incidence of fungi species in Portuguese apples varieties from Beira Alta region; (2) to evaluate PAT levels in apples; and (3) to correlate the incidence of fungi genera with apple variety and PAT production.

\section{MATERIALS AND METHODS}

\subsection{Samples}

Six apples varieties (Bravo de Esmolfe, Golden, Starking, Fuji, Reineta Parda, and Gala Galaxy) were harvested at commercial maturity from an orchard in the Beira Alta region (Mangualde, north of Portugal) and randomized on the same day of harvest. A total of 84 fresh apple samples (twenty four Starking apples and twelve fruits of the other apple varieties) from 2011 season were used in this study. Only undamaged and disease-free fruit were used in the experiments. The selection was conducted in order to include a large number of varieties, especially those ones dominant in the Portuguese market and also the most uses in fruit juice production. The apples were stored at room temperature in the absence of light until they were partially rotted (the diameter of the lesion must represent about one quarter of the apple). Each apple variety was stored in an apple fruit packaging box and 
each apple was separated from neighbouring apple about $10 \mathrm{~cm}$.

\subsection{Isolation and Identification of Fungal Species}

Healthy and rotted apples were analyzed. Fungi were isolated from the pulp of the apple, each apple surface was washed twice with sterile distilled water, and the pulp was separated from the skin under aseptic conditions. For fungal isolation from rotted apples, were used small pieces selected from the margins of decay lesions from apple fruits.

For isolation of fungi from apples, were used a plating method, adapted from Portuguese standard procedure [26]. Ten grams of each sample were homogenized in $90 \mathrm{~mL}$ of sterile tryptone-salt solution in a Colworth 400 Stomacher (Seward Medical, London, UK) for 60 seconds. Consecutive decimal dilutions were performed by adding $1 \mathrm{~mL}$ of the previous dilution to a test tube containing $9 \mathrm{~mL}$ of tryptone-salt solution. For enumeration and identification at genus level of molds, $1 \mathrm{~mL}$ of each dilution was spread into each of five plates (0.2 $\mathrm{mL} /$ plate) of Cook Rose Bengal Agar (DRCB, Oxoid, CM 727, Suplement-chloranphenicol SR 78), and plates were incubated at $27^{\circ} \mathrm{C}$ for 5 days.

Fungal colonies were transferred to individual slants of potato dextrose agar ( $200 \mathrm{~g}$ potato infusion, $20 \mathrm{~g}$ dextrose, $15 \mathrm{~g}$ agar per $1000 \mathrm{~mL}$ of deionised water) (PDA). This medium was also used to maintain the isolates at $4{ }^{\circ} \mathrm{C}$. Identification of all isolates was achieved through macroscopic and microscopic observation in accordance with guidelines published for each genus [27].

\subsection{Chemical Analysis}

\subsubsection{Reagents and Standard Solutions}

Ethyl acetate, n-hexane and acetonitrile (all HPLC grade), and ethanol, acetic acid and anhydrous sodium hydrogen carbonate (all extra pure grade), perchloric acid $60 \%$ and anhydrous sodium sulphate (p.a.), and sand (purified), all were purchased from Merck (VWR, Portugal). The PAT standard was ordered from Sigma (Dias de Sousa, Portugal). Water was ultra pure (Milli$Q$ from Millipore, Interface, Portugal).

Stock solution with $200 \mathrm{mg} / \mathrm{L}$ of PAT was prepared in ethyl acetate. This solution was stored at $-20{ }^{\circ} \mathrm{C}$ and when necessary appropriate volume was evaporated and diluted with methanol for the preparation of an intermediate standard solution. The concentration of the PAT intermediate standard solution was determined by UV at $276 \mathrm{~nm}$, against a solvent blank, using the molar extinction value. Appropriate amounts of the intermediate standard solution were diluted with $0.1 \%$ acetic acid in order to get final concentrations for calibration curves (10 - 200 $\mu \mathrm{g} / \mathrm{L})$.

\subsubsection{Sample Preparation for Patulin Determination}

In order to determine PAT accumulation, necrosed tissue was removed from the apple. Considering that PAT can diffuse to the sound tissue [22], apple flesh was cut $1 \mathrm{~cm}$ below the decay tissue. A $10 \mathrm{~g}$ of rotten apple sample was weighed and analyzed immediately. Another $10 \mathrm{~g}$ of flesh apple near rotted apple was also weighed and analyzed.

\subsubsection{Analysis of Patulin in Apples by HPLC-UV Analysis}

The HPLC apparatus was a Waters Alliance 2695 system equipped with a photodiode array detector, Waters 2996, set at $276 \mathrm{~nm}$ and with a $50 \mu \mathrm{L}$ loop. Data collection and subsequent processing were performed using the Waters Millenium software. A stainless steel analytical column $(250 \times 4.6 \mathrm{~mm}$ i.d., 5 $\mu \mathrm{m}, \mathrm{RP}$ C18; Merck, VWR, Portugal) was used. The mobile phase, eluting at a flow rate of $0.5 \mathrm{~mL} / \mathrm{min}$, consisted of an isocratic mixture of water-acetonitrileperchloric acid (96:4:0.1) for 20 min followed by a $5 \mathrm{~min}$ gradient washing step which starts with a concentration of $100 \%$ acetonitrile and ends with a concentration of $65 \%$ acetonitrile in water. Fifty microliters were injected onto the HPLC column.

PAT extraction, the clean-up procedure and preparation of stock standard solutions were performed according to conditions described by Arranz [28] and previously tested and validated by some researchers of the our group [9]. The method was adapted for the new conditions (different laboratory, other equipment, and change of sample loop) and in-house validated.

Apple sample (rotted and fresh apple) was extracted with an ethyl acetate extraction solvent in the presence of sodium sulfate and sodium hydrogen carbonate and was then cleaned up over an unconditioned silica gel solid-phase extraction (SPE) column (Strata Si $500 \mathrm{mg} / 3 \mathrm{ml}$, Phenomenex, Tecnocroma, Portugal).

The purified extract was evaporated to dryness and redissolved in aqueous acetic acid solution $(\mathrm{pH} 4)$. The redissolved samples were filtered through a membrane 
filter (Millex $0.45 \mu \mathrm{m}$, Millipore) and the filtrate transferred to HPLC vials. Samples were injected twice in reverse-phase (RP) HPLC and PAT was quantitatively determined by UV detection at $276 \mathrm{~nm}$. Mean PAT values was calculated and expressed as $\mu \mathrm{g} / \mathrm{kg}$.

\subsection{In-House Validation}

The validation parameters examined were linearity, detection and quantification limits (LOD and LOQ), repeatability, reproducibility, accuracy, and recovery. Linearity was studied for two concentration ranges: low range $(10-63 \mu \mathrm{g} / \mathrm{L})$ and high range $(55-193 \mu \mathrm{g} / \mathrm{L})$. Six solutions containing PAT at different concentration levels were analysed by HPLC-UV. The calibration curve was plotted applying least-square regression analysis. Linearity was evaluated by the values of determination coefficients and coefficient of variation of the method, and after application of Mandel test, RIKILT test [29] and homogeneity of variance analysis [30]. The results were treated in order to comply with all the defined limits for each statistical test.

The LOD and LOQ of HPLC-UV were based in standard deviations of ten replicates of lower concentration of each linear range $(10 \mu \mathrm{g} / \mathrm{L}$ and $60 \mu \mathrm{g}$ $/ L)$ and using the formula ( $3 \times$ standard deviation) and (10 $\mathrm{x}$ standard deviation), respectively.

The repeatability and intra-laboratory reproducibility of the HPLC-UV method was evaluated after analysis of three concentration levels of the linear range, in different days.

The LOD and LOQ of the SPE-HPLC-UV method (global method) were calculated for apples matrices at one concentration level. Ten apple samples were spiked with $10 \mu \mathrm{g} / \mathrm{L}(4.0 \mu \mathrm{g} / \mathrm{kg})$ of PAT. The LOD and $\mathrm{LOQ}$ were also calculated using the formula $(3 \times \mathrm{SD})$ and $(10 \times S D)$, respectively.

The repeatability and intra-laboratory reproducibility of the global method were also studied in apple matrices at two concentration levels. The repeatability and intra-laboratory reproducibility of the method were expressed as a relative standard deviation, RSDr and $\mathrm{RSD}_{R 1}$, respectively.

Accuracy was evaluated by recovery studies (matrix effect) and the analysis of three control solutions (10 $\mu \mathrm{g} / \mathrm{L}, 60 \mu \mathrm{g} / \mathrm{L}$ and $200 \mu \mathrm{g} / \mathrm{L}$ ) in each work set. Matrix effect was evaluated in recovery studies using different varieties of apples fortified at the same concentrations levels.

The accuracy was expressed as RSD (\%) and relative error (\%).

\section{RESULTS AND DISCUSSION}

\subsection{In-House Validation: SPE-HPLC/UV Method}

The linear range, the determination coefficient, the PG values, the $F$ value of Fisher/Snedecor (tabulated value), the coefficient of variation of the method, the residuals analysis, the RIKILT test and limit of detection and limit of quantification for each compound are given in Table 1.

All calibration curves fulfilled all the requirements for a linear method with determination coefficients higher than 0.995 , coefficient of variation lower of $2.0 \%$ and $P G$ values lower than the tabulated value of the Fisher/Snedecor.

Table 1: Regression Data for Patulin by HPLC-UV Method

\begin{tabular}{|c|c|c|}
\hline Calibration curve & $\begin{array}{c}\text { Low Range } \\
(\mathbf{N}=6)\end{array}$ & $\begin{array}{c}\text { High range } \\
(\mathbf{N}=\mathbf{1 1})\end{array}$ \\
\hline \hline Linear range, $(\mu \mathrm{g} / \mathrm{L})$ & $10-63-193$ \\
\hline Slope, $\mathrm{b}$ & 159.7 & 162.6 \\
\hline Intercept, a & 309.32 & 1451.59 \\
\hline $\mathrm{r}^{2}$ & 0.9992 & 0.9972 \\
\hline $\mathrm{CV}$ m $\%$ & 1.7 & 1.8 \\
\hline RIKILT test $(\%)$ & {$[93-105]$} & {$[94-106]$} \\
\hline Mandel test, PG $\leq \mathrm{F}(1 ; \mathrm{N}-3 ; 95 \%)$ & $0.17<10.1$ & $0.08<5.3$ \\
\hline Homogeneity of variance analysis, PG $\leq \mathrm{F}(\mathrm{N}-1 ; \mathrm{N}-1 ; 99 \%)$ & $3.4<5.4$ & $5.0<5.4$ \\
\hline
\end{tabular}

$\mathbf{N}=$ The number of data points; $\mathbf{F}=$ Value of Fisher/Snedecor (tabulated value). 
The calibration curves in these two linear ranges were precise and both show a working range well defined ( $P G \leq F(N-1 ; N-1 ; 99 \%)$.

\subsection{Repeatability and Intralaboratory Repro- ducibility of the Chromatographic Method}

The precision results of the HPLC-UV method using repeatability conditions had a RSD of $2.8 \%, 2.1 \%$ and $1.5 \%$ for the PAT concentration of the of $10 \mu \mathrm{g} / \mathrm{L}, 60$ $\mu \mathrm{g} / \mathrm{L}$ and $200 \mu \mathrm{g} / \mathrm{L}$, respectively.

The intralaboratory reproducibility results of the HPLC-UV method ( $\mathrm{N}=51,5$ days) had an RSD of 3.1 $\%, 6.2 \%$ and $3.5 \%$ for the PAT concentration of the 10 $\mu \mathrm{g} / \mathrm{L}, 60 \mu \mathrm{g} / \mathrm{L}$ and $200 \mu \mathrm{g} / \mathrm{L}$, respectively.

The results in both conditions and for three concentration levels tested shows a RSD lower than $10 \%$, therefore, the chromatographic method had a good precision.

\subsection{Analytical Limits}

The values of limit of detection (LOD) and limit of quantification (LOQ) of the chromatographic method calculated under repeatability conditions were 0.97 and $3.2 \mu \mathrm{g} / \mathrm{L}$ which reflects PAT levels of $0.39 \mu \mathrm{g} / \mathrm{kg}$ and $1.3 \mu \mathrm{g} / \mathrm{kg}$, respectively.

The LOD and LOQ of the global method (SPEHPLC-UV) for apple matrix were $1.7 \mu \mathrm{g} / \mathrm{kg}$ and 5.5 $\mu \mathrm{g} / \mathrm{kg}$, respectively.

\subsection{Repeatability, Inter/Intra Laboratory Repro- ducibility and Recovery}

Method accuracy was also determined by the analysis of three standard controls of linear range (Table 2).

Table 2: Accuracy Studies for Patulin by HPLC-UV Method: Percentage Errors and Relative Standard Deviation (RSD, \%) of Patulin Standard Controls $(n=10)$

\begin{tabular}{|c|c|c|}
\hline $\begin{array}{c}\text { Standard control } \\
(\mu \mathrm{g} / \mathrm{L})\end{array}$ & $\begin{array}{c}\text { Percentage error } \\
(\%)\end{array}$ & $\begin{array}{c}\text { RSD } \\
(\%)\end{array}$ \\
\hline \hline 10 & 5.4 & 2.8 \\
\hline 60 & 4.5 & 5.1 \\
\hline 200 & 3.0 & 3.5 \\
\hline
\end{tabular}

Percentage errors were between 3.0 and $5.4 \%$ for the standard control of the $200 \mu \mathrm{g} / \mathrm{L}$ and $10 \mu \mathrm{g} / \mathrm{L}$, respectively, with a relative standard deviation lower than $10 \%$. Concerning the reported values the method showed a good precision and accuracy.

According to the requirements of the European Commission [31] it may be considered acceptable an $\mathrm{RSD}_{\mathrm{r}} \leq 30 \%$ and an $\mathrm{RSD}_{\mathrm{r}} \leq 20 \%$ for PAT concentrations lower than $20 \mu \mathrm{g} / \mathrm{kg}$ and between 20 and $50 \mu \mathrm{g} / \mathrm{kg}$, respectively.

The relative standard deviation for repeatability $\left(R_{S D}\right)$ for the spiking levels of 4 and $24 \mu \mathrm{g} / \mathrm{kg}$ was 14 and $11 \%$, respectively.

The values of intralaboratory reproducibility $\left(R \mathrm{RD}_{\mathrm{RI}}\right)$ for the assayed matrices at the spiking levels of 4 and $24 \mu \mathrm{g} / \mathrm{kg}$ were $20 \%$ and $16 \%$, respectively. So, the method was shown a good precision.

The recoveries values were between 80 and $102 \%$. These values are acceptable according to the requirements of Commission Regulation [31] (recovery between $50-120 \%$ and $70-105 \%$ for PAT concentrations lower than $20 \mu \mathrm{g} / \mathrm{kg}$ and between $20-50 \mu \mathrm{g} / \mathrm{kg}$, respectively).

\subsection{Analysis of Patulin in Apples}

The in-house validated method of SPE-HPLC-UV was used to analyze the presence of PAT in 84 apples of six varieties. Table 3 shows the analysed apples varieties, the percentage of contaminated apples and the concentration of PAT (Table 3). The PAT levels in flesh apple near rotted apple were not detected in all apple variety samples.

According to results presented on Table 3, this study revealed an incidence of positive samples of $23 \%$ (19 apples with PAT) and a maximum detected value of $196 \mathrm{mg} / \mathrm{kg}$.

Concerning the analysed apples, the incidence of positive samples was higher in Bravo Esmolfe apple (45\%). Fuji and Gala apple varieties showed a negative incidence of PAT. The median values are similar for Starking and Golden variety, $31 \mu \mathrm{g} / \mathrm{kg}$ and $33 \mu \mathrm{g} / \mathrm{kg}$, respectively and, also for Bravo Esmolfe and Reineta apple variety, $110 \mu \mathrm{g} / \mathrm{kg}$ and $101 \mu \mathrm{g} / \mathrm{kg}$, respectively.

In contaminated apples with PAT was predominant genus Penicillium spp. inferring that was mainly responsible for the production of PAT in apples (Table 4).

Fungi of the genera Cladosporium spp., Alternaria spp., Fusarium spp., and Aspergillus spp. were also 
Table 3: Patulin Production by Several Varieties of Apples

\begin{tabular}{|c|c|c|c|c|c|c|c|}
\hline \multirow{2}{*}{ Apple variety } & \multicolumn{2}{|c|}{ Rotted apples } & \multicolumn{2}{|c|}{ Apples with patulin } & \multicolumn{3}{|c|}{$\mu g / K g$ Patulin } \\
\hline & Number & Percentage (\%) & Number & Percentage (\%) & Minimum & Maximum & Median \\
\hline Starking & 24 & 100 & 8 & 33 & 6 & 9989 & 31 \\
\hline Bravo Esmolfe & 11 & 92 & 5 & 45 & 11 & 196434 & 110 \\
\hline Fuji & 11 & 92 & 0 & 0 & - & - & - \\
\hline Golden & 9 & 75 & 2 & 22 & 13 & 54 & 33 \\
\hline Gala Galaxy & 6 & 50 & 0 & 0 & - & - & - \\
\hline
\end{tabular}

Table 4: Genera Isolated from Apples Varieties and Relationship with Patulin Production

\begin{tabular}{|c|c|c|c|c|c|c|c|c|c|c|}
\hline \multirow{4}{*}{$\begin{array}{l}\frac{7}{0} \\
\frac{0}{\frac{1}{2}} \\
\frac{0}{2} \\
\frac{0}{2}\end{array}$} & \multicolumn{10}{|c|}{ Production of patulin } \\
\hline & Yes & No & Yes & No & Yes & No & Yes & No & Yes & No \\
\hline & \multicolumn{10}{|c|}{ Incidence of genera in contaminated apples (\%) } \\
\hline & \multicolumn{2}{|c|}{ Penicillium } & \multicolumn{2}{|c|}{ Cladosporium } & \multicolumn{2}{|c|}{ Alternaria } & \multicolumn{2}{|c|}{ Fusarium } & \multicolumn{2}{|c|}{ Aspergillus } \\
\hline Starking & 73 & 40 & 5 & 7 & 5 & 1 & 3 & 0 & 0 & 3 \\
\hline Bravo Esmolfe & 37 & 22 & 16 & 20 & 4 & 3 & 0 & 0 & 4 & 7 \\
\hline Reineta Parda & 65 & 46 & 10 & 17 & 10 & 9 & 5 & 3 & 0 & 3 \\
\hline Fuji & - & 29 & - & 16 & - & 9 & - & 0 & - & 0 \\
\hline Golden & 75 & 24 & 10 & 17 & 0 & 0 & 0 & 3 & 0 & 9 \\
\hline Gala Galaxy & - & 33 & - & 7 & - & 3 & - & 3 & - & 3 \\
\hline
\end{tabular}

identified, even in apples where there was no production of PAT.

The variety with the highest levels of PAT was Bravo Esmolfe; however it showed the lowest prevalence of Penicillium spp. compared to other varieties of apples which was detected PAT.

PAT was not detected in any of the varieties of Fuji and Gala apples, although these apple varieties show the fungi normally associated with the production of PAT. Thus, these two varieties may be the most suitable for the production of apple based-foods.

The different PAT accumulation could be due to acidity and sugar conditions in theses apples varieties [32].
These data only allow us to relate the production of patulin with the fungal genera. In the future, we should have new approaches, change the acidity and sugar content in the culture media seeded with these fungi genera and study its influence in the production of patulin.

The apples variety seems to be an important factor to PAT production which is according to the results obtained by other authors [18,20].

\section{CONCLUSIONS}

The described method is adequate for the analysis of a large variety of apples and meets the requirements of validation and quality control purposed for these 
procedures. Our approach is useful to define the mycoflora of apples and PAT levels in apples that will be used in apple based-foods.

The mycoflora of apples was composed mainly by Penicillium spp with exception of Fuji and Gala apples. The incidence of PAT was associated to the presence of Penicillium spp. Fuji and Gala apples are the most suitable apples for the production of apple based-foods because there was no production of PAT.

\section{ACKNOWLEDGEMENTS}

The authors would like to thank Cooperativa Agrícola de Mangualde delivery of the various varieties of apples, without which it would not have been possible to perform this work.

\section{REFERENCES}

[1] European Food Safety Authority (EFSA), Committed to ensuring that Europe's food is safe [homepage on the internet]. Topics, Contaminants in food and feed, [updated 2014 Nov 7; cited 2015 Jan 8]: Available from: http: //www.efsa.europa.eu/en/topics/topic/mycotoxins.htm

[2] Speijers G, Speijers M. Combined toxic effects of mycotoxins. Toxicol Lett 2004; 153(1): 91-8. http://dx.doi.org/10.1016/.toxlet.2004.04.046

[3] Wouters, M F A, Speijers, G J A. Patulin. Food additives series 35.Toxicological evaluation of certain food additives and contaminants Geneva, Switzerland: World Health Organization; 1995.

[4] IARC (International Agency for Research on Cancer). IARC monographs on the evaluation of carcinogenic risk of chemicals to humans. Some naturally occurring and synthetic food components, furocoumarins and ultraviolet radiation. Vol. 40.Lyon, France: IARC 1995.

[5] Tangni E, Theys R, Mignolet E, Maudoux M, Michelet J, Larondelle Y. Patulin in domestic and imported apple-based drinks in Belgium: occurrence and exposure assessment. Food Add Cont 2003; 20(5): 482-9. http://dx.doi.org/10.1080/0265203031000093204

[6] Baert K, De Meulenaer B, Kamala A, Kasase C, Devlieghere F. Occurrence of patulin in organic, conventional, and handcrafted apple juices marketed in Belgium. J Food Prot 2006; 69(6): 1371-8.

[7] Beretta B, Gaiaschi A, Galli C, Restani P. Patulin in applebased foods: occurrence and safety evaluation. Food Addit Contam 2000; 17(5): 399-406 http://dx.doi.org/10.1080/026520300404815

[8] Sabater-Vilar M, Maas R, De Bosschere H, Ducatelle R, Fink-Gremmels J. Patulin produced by an Aspergillus clavatus isolated from feed containing malting residues associated with a lethal neurotoxicosis in cattle. Mycophatologia 2004; 158(4): 419-26. http://dx.doi.org/10.1007/s11046-005-2877-x

[9] Barreira M, Alvito $P$, Almeida C. Occurrence of patulin in apple-based-foods in Portugal. Food Chem 2010; 121(3): 653-8.

http://dx.doi.org/10.1016/j.foodchem.2009.12.085

[10] Marin S, Morales H, Hasan H, Ramos A, Sanchis V. Patulin distribution in Fuji and Golden apples contaminated with Penicillium expansum. Food Add Cont 2006; 23(12): 131622.
[11] Murillo-Arbizu M, Amezqueta S, Gonzalez-Penas E, de Cerain A. Occurrence of patulin and its dietary intake through apple juice consumption by the Spanish population. Food Chem 2008; 113(2): 420-3.

http://dx.doi.org/10.1016/j.foodchem.2008.07.054

[12] Piemontese L, Solfrizzo M, Visconti A. Occurrence of patulin in conventional and organic fruit products in Italy and subsequent exposure assessment. Food Addit Contam 2005; 22(5): 437-42.

http://dx.doi.org/10.1080/02652030500073550

[13] Moukas A, Panagiotopoulou V, Markaki P. Determination of patulin in fruit juices using HPLC-DAD and GC-MSD techniques. Food Chem 2008; 109(4): 860-7. http://dx.doi.org/10.1016/j.foodchem.2008.01.015

[14] Boonzaaijer G, Bobeldijk I, van Osenbruggen W. Analysis of patulin in dutch food, an evaluation of a SPE based method. Food Control 2005; 16(7): 587-91. http://dx.doi.org/10.1016/i.foodcont.2004.06.020

[15] WHO (World Health Organization). Evaluation of certain food additives and contaminants (Forty-fourth report of the Joint FAO/WHO Expert Committee on Food Additives). WHO Technical Report Series, No. 859, 36-38. In). Geneva 1995.

[16] European Commission, Commission Regulation (EC) $1881 / 2006$ of 19 December 2006. Official Journal of the European Communities L364.

[17] Moake M, Padilla-Zakour O, Worobo R. Comprehensive review of patulin control methods in foods. Compr Rev Food Sci Food Saf 2005; 4(1): 8-21. http://dx.doi.org/10.1111/j.1541-4337.2005.tb00068.x

[18] Marin S, Mateo E, Sanchis V, Valle-Algarra F, Ramos A, Jimenez M. Patulin contamination in fruit derivatives, including baby food, from the Spanish market. Food Chem 2011; 124(2): 563-8.

http://dx.doi.org/10.1016/j.foodchem.2010.06.072

[19] Senyuva H, Gilbert J, Samson R, Ozcan S, Ozturkoglu S, Onal D. Occurrence of fungi and their mycotoxins in individual Turkish dried figs. World Mycotoxin J 2008; 1(1): 79-86.

http://dx.doi.org/10.3920/WMJ2008.x009

[20] Menniti A, Neri F, Gregori R, Maccaferri M. Some factors influencing patulin production by Penicillium expansum in pome fruits. J Sci Food Agric 2010; 90(13): 2183-7. http://dx.doi.org/10.1002/jsfa.4067

[21] Neri F, Donati I, Veronesi F, Mazzoni D, Mari M. Evaluation of Penicillium expansum isolates for aggressiveness, growth and patulin accumulation in usual and less common fruit hosts. International J Food Microb 2010; 143(3): 109-17. http://dx.doi.org/10.1016/j.ijfoodmicro.2010.08.002

[22] Welke J, Hoeltz M, Dottori H, Noll I. Paatulin accumulation in apples during storage by Penicillium expansum and Penicillium griseofulvum strains. Braz J Microb 2011; 42(1): $172-80$.

http://dx.doi.org/10.1590/S1517-83822010005000006

[23] Martins M, Gimeno A, Martins H, Bernardo F. Co-occurrence of patulin and citrinin in Portuguese apples with rotten spots. Food Addit Contam 2002; 19(6): 568-74. http://dx.doi.org/10.1080/02652030210121320

[24] Tournas V, Memon S. Internal contamination and spoilage of harvested apples by patulin-producing and other toxigenic fungi. International J Food Microb . 2009; 133(1-2): 206-9. http://dx.doi.org/10.1016/j.ijfoodmicro.2009.05.025

[25] FAO (Food and Agriculture Organisation of the United States). Statistical Yearbook (FAOSTAT), 2013. NP-3277: 1987.

[26] Norma Portuguesa. Microbiologia: contagem de bolores e leveduras a $25 \stackrel{\circ}{\circ}$ (Microbiology: General guidance for enumeration of yeasts and moulds - colony count technique at $25 \stackrel{\circ}{\mathrm{C}) \text {. }}$

[27] De Hoog, G S, Guarro, J, Gené, J, Figueras, M J. Atlas of Clinical Fungi. 2nd Edition ed. Centraalbureau voo 
Schimmelcultures, Utrecht, The Netherlands, and University Rovira i Virgili, Reus, Spain: 2000.

[28] Arranz I, Derbyshire M, Kroeger K, Mischke C, Stroka J, Anklam E. Liquid chromatographic method for quantitation of patulin at $10 \mathrm{ng} / \mathrm{mL}$ in apple-based products intended for infants: Interlaboratory study. J AOAC Int 2005; 88(2): 51825.

[29] van Trijp, J, AH, R. RIKILT-DLO, Model for the calculation of calibration curves, RIKILT report 91.02. Wageningen, The Netherlands; 1991.

[30] ISO (International Organization for Standardization). ISO Standards Compendium - Environmental Water Quality, vol. I, 1st Ed., 1994. ISO 8466-1. Water quality - Calibration and
Evaluation of Analytical Methods and Estimation of Performance Characteristics; Part I: Statistical Evaluation of the Linear Calibration Function (1990).

[31] European Commission, Commission Regulation (EC) 401/2006 of 23 February 2006. Official Journal of the European Communities L70/12-34.

[32] Feliciano $R$, Antunes C, Ramos A, Serra A, Figueira M, Duarte $C$, et al. Characterization of traditional and exotic apple varieties from Portugal. Part 1-Nutritional, phytochemical and sensory evaluation. J Functional Foods 2010; 2(1): 35-45.

http://dx.doi.org/10.1016/j.jff.2009.12.004 